\title{
Pulmonary metastases from uterine malignancies: Results of surgical resection in 133 patients
}

\author{
Masaki Anraku, MD \\ Kohei Yokoi, MDa \\ Ken Nakagawa, $M D^{\mathrm{b}}$ \\ Takehiko Fujisawa, MD ${ }^{\mathrm{c}}$ \\ Jun Nakajima, MD ${ }^{d}$ \\ Hirohiko Akiyama, $\mathrm{MD}^{\mathrm{e}}$ \\ Yoshihiro Nishimura, $\mathrm{MD}^{f}$ \\ Koichi Kobayashi, MD \\ The Metastatic Lung Tumor Study \\ Group of Japan
}

From the Division of Thoracic Surgery, Tochigi Cancer Center, ${ }^{a}$ Tochigi, Japan; Department of Chest Surgery, Cancer Institute Hospital, ${ }^{\text {b }}$ Tokyo, Japan; Department of Thoracic Surgery, Chiba University, ${ }^{c}$ Chiba, Japan; Department of Cardiothoracic Surgery, University of Tokyo, ${ }^{\mathrm{d}}$ Tokyo, Japan; Department of Thoracic Surgery, Saitama Cancer Center, ${ }^{\mathrm{e}}$ Saitama, Japan; Department of Surgery, Tokyo Metropolitan Komagome Hospital, ${ }^{\mathrm{f}}$ Tokyo, Japan; and Department of Thoracic Surgery, Keio University School of Medicine, ${ }^{g}$ Tokyo, Japan.

For a listing of participating institutions, see appendix.

Received for publication May 20, 2003; revisions requested Sept 28, 2003; accepted for publication Oct 6, 2003.

Address for reprints: Kohei Yokoi, MD, Tochigi Cancer Center, Division of Thoracic Surgery, 4-9-13 Yohnan, Utsunomiya, Tochigi 320-0834, Japan (E-mail: kyokoi@tcc.pref.tochigi.jp).

J Thorac Cardiovasc Surg 2004;127:1107-12 $0022-5223 / \$ 30.00$

Copyright $\odot 2004$ by The American Association for Thoracic Surgery

doi:10.1016/j.jtcvs.2003.10.011
Objective: The long-term results of the surgical treatment for patients with pulmonary metastases from uterine malignancies were clarified.

Methods: A total of 133 patients who underwent pulmonary metastasectomy for uterine malignancies were enrolled in the Metastatic Lung Tumor Study Group of Japan between March 1984 and February 2002. These patients constituted the study population, and their clinical, pathologic, and prognostic data were retrospectively analyzed.

Results: The morbidity and mortality rates related to the operation were minimal ( $1 \%$ and $1 \%$, respectively). The 5- and 10-year survivals after the surgical resection in all cases were $54.6 \%$ and $44.9 \%$, respectively. The 5-year survivals for each histologic type were estimated to be $46.8 \%$ for squamous cell carcinoma $(\mathrm{n}=58)$, $40.3 \%$ for cervical adenocarcinoma $(\mathrm{n}=13), 75.7 \%$ for endometrial adenocarcinoma $(\mathrm{n}=23), 86.5 \%$ for choriocarcinoma $(\mathrm{n}=16)$, and $37.9 \%$ for leiomyosarcoma $(\mathrm{n}=11)$. In the univariate analysis, the following were shown to be associated with poor survival: primary tumor in the cervix, short disease-free interval $(<12$ months), large number of resected metastases $(\geq 4)$, and large tumor size $(\geq 3 \mathrm{~cm})$. After mutual adjustment, short disease-free interval ( $<12$ months) alone was related to risk of death (hazard ratio $=2.26,95 \%$ confidence interval $=1.06-4.78$ ) for 105 patients, excluding patients with choriocarcinoma and miscellaneous histologic types.

Conclusion: Pulmonary metastasectomy for uterine malignancies is a safe and acceptable treatment to improve survival. Patients with a disease-free interval of 12 months or more are good candidates for this treatment if there is adequate control of the primary tumor without extrapulmonary metastasis.

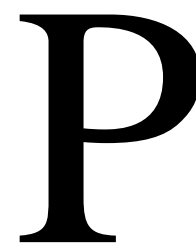
ulmonary metastasectomy has been widely adopted for treatment in properly selected patients with metastases isolated to the lung. Survival after pulmonary resections varies among different primary tumor types. ${ }^{1}$ Trek $^{2}$ first reported a patient who underwent pulmonary resection for metastatic uterine adenocarcinoma in 1930. After that report, some investigators reported patients with uterine cancer with pulmonary metastases, treated with or without resection. ${ }^{3-6}$ However, the surgical results of pulmonary metastasectomy for uterine malignancies have been inadequate in large series of patients. This study analyzes the clinical and pathologic informa- 
TABLE 1. Characteristics of 133 patients who underwent surgical resection for pulmonary metastases from uterine malignancies

\begin{tabular}{|c|c|}
\hline Characteristic & $\begin{array}{c}\text { No. of } \\
\text { patients }\end{array}$ \\
\hline \multicolumn{2}{|l|}{ Histology } \\
\hline \multicolumn{2}{|l|}{ Cervix } \\
\hline Squamous cell carcinoma & 58 \\
\hline Adenocarcinoma & 13 \\
\hline Others & 5 \\
\hline \multicolumn{2}{|l|}{ Body } \\
\hline Endometrial adenocarcinoma & 23 \\
\hline Choriocarcinoma & 16 \\
\hline Leiomyosarcoma & 11 \\
\hline Others & 7 \\
\hline \multicolumn{2}{|l|}{ Disease-free interval $(\mathrm{mo})^{*}$} \\
\hline 0 & 8 \\
\hline $1-11$ & 23 \\
\hline $12-35$ & 38 \\
\hline$\geq 36$ & 60 \\
\hline Unknown & 4 \\
\hline \multicolumn{2}{|l|}{ Number of resected metastases } \\
\hline 1 & 77 \\
\hline $2-3$ & 31 \\
\hline$\geq 4$ & 23 \\
\hline Unknown & 2 \\
\hline \multicolumn{2}{|l|}{ Tumor size $(\mathrm{cm})$} \\
\hline$<3.0$ & 71 \\
\hline$\geq 3.0$ & 52 \\
\hline Unknown & 10 \\
\hline \multicolumn{2}{|l|}{ Surgical approach } \\
\hline Unilateral & 95 \\
\hline Bilateral & 38 \\
\hline \multicolumn{2}{|l|}{$\begin{array}{c}\text { Type of resection (second resection } \\
\text { of the staged operation) } t\end{array}$} \\
\hline Pneumonectomy & $3(0)$ \\
\hline Bilobectomy & $3(0)$ \\
\hline Lobectomy & $60(1)$ \\
\hline Wedge resection and/or & $67(17)$ \\
\hline segmentectomy & \\
\hline \multicolumn{2}{|l|}{ Lymphadenectomy } \\
\hline Performed & 45 \\
\hline Not performed & 49 \\
\hline Unknown & 39 \\
\hline
\end{tabular}

tion and prognostic variables of a large number of patients undergoing pulmonary resection for metastatic uterine malignancies.

\section{Patients and Methods}

Between March 1984 and February 2002, 133 female patients who underwent pulmonary resection for metastatic uterine malignancies were registered in the Metastatic Lung Tumor Study Group of Japan. The clinical, pathologic, and prognostic data were obtained from the registry in a retrospective fashion. The selection of patients for surgical treatment or the operative procedure depended on each institution. There was no unified guideline for the operative approach. Follow-up was performed at each institution. Operative mortality was defined as death within the first 30 days postoperatively or during hospitalization.

Survival was measured from the initial pulmonary metastasectomy until death or the last date of the follow-up (October 11, 2002), and the data were reported as mean and $95 \%$ confidence intervals (CIs). The survival curves according to selected clinical and pathologic characteristics were calculated with the KaplanMeier method, ${ }^{7}$ and comparisons among the curves were made with the log-rank test. Subsequently, we performed a multivariable analysis to clarify an independent effect of each characteristic on survival using a Cox proportional hazards model. ${ }^{8}$

\section{Results}

The mean age of the patients at thoracotomy was 56.4 years (range 26-80 years). The patients' characteristics are shown in Table 1. A total of 77 of the 133 patients $(58 \%)$ underwent surgery for a single metastasis, and 23 patients (17\%) underwent surgery for 4 or more metastases. The diseasefree interval (DFI), defined as the time between treatment of the primary site and detection of lung metastases, ranged from 0 to 243 months. Pulmonary metastases were detected simultaneously with the primary tumor $(\mathrm{DFI}=0)$ in 8 patients $(6 \%)$. The DFI was less than 12 months in 23 patients (17\%), whereas it was more than 36 months in 60 patients (45\%). Thirty-eight patients (29\%) underwent bilateral thoracotomy for complete tumor removal, 18 of whom underwent staged operations. Repeated metastasectomy was distinguished from a staged operation. Of 12 patients undergoing repeated metastasectomy for recurrent disease after the initial pulmonary resection, 2 patients underwent 3 metastasectomies and 1 patient underwent 4 metastasectomies. Forty-five patients (34\%) underwent mediastinal or hilar lymphadenectomy, or both. Among them, 16 patients had pathologically positive lymph nodes. Eight patients $(6 \%)$ had extrapulmonary metastases at the time of lung metastasectomy.

There was 1 postoperative death as the result of cardiac infarction (mortality rate 1\%). In the total of 166 operations in the 133 patients, there were 2 postoperative major complications (morbidity rate $1 \%$ ): wound infection and liver dysfunction.

Median follow-up time was 40 months with a range of 0 to 220 months, and overall cumulative 5-year and 10-year survivals in the 133 patients were $54.6 \%$ (95\% CI, 45.9\%$63.9 \%$ ) and $44.9 \%$ (95\% CI, 34.3\%-55.5\%), respectively. The patients with a primary tumor in the cervix had a 5-year survival of $45.7 \%$ (95\% CI, 33.2\%-58.2\%), and the patients with a tumor in the body had a 5-year survival of $66.3 \%$ (95\% CI, 53.0\%-79.5\%) $(P=.01)$. The 5-year survivals in different histologic types were calculated as $46.8 \%$ (95\% CI, 32.3\%-61.2\%) in squamous cell carcinoma, $40.3 \%$ (95\% CI, $11.6 \%-69.0 \%$ ) in cervical adenocarcinoma, $75.7 \%$ 


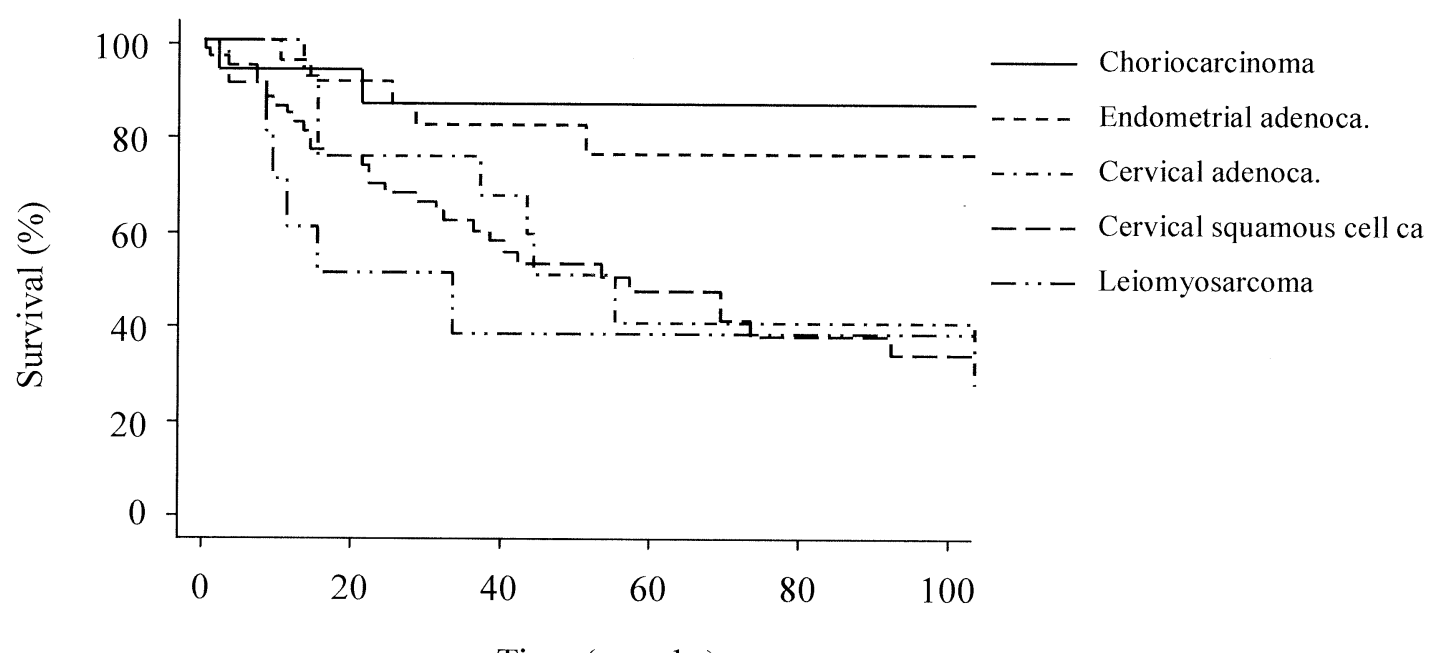

Patients at risk

Time (months)

\begin{tabular}{|c|c|c|c|c|c|}
\hline Choriocarcinoma & 16 & 13 & 12 & 10 & 9 \\
\hline Cervical adenoca. & 13 & 9 & 8 & 3 & 3 \\
\hline Endometrial adenoca. & 23 & 20 & 16 & 11 & 9 \\
\hline Cervical squamous cell ca. & 58 & 41 & 24 & 16 & 9 \\
\hline Leiomyosarcoma & 11 & 5 & 3 & 2 & 1 \\
\hline
\end{tabular}

Figure 1. Survival curves from the time at initial metastasectomy: influence of histologic type.

(95\% CI, 56.7\%-94.6\%) in endometrial adenocarcinoma, $86.5 \%(95 \% \mathrm{CI}, 69.1 \%-100 \%)$ in choriocarcinoma, and $37.9 \%(95 \%$ CI, 6.3\%-69.5\%) in leiomyosarcoma (Figure 1). Among patients with pulmonary metastases from cervical cancers, there was no significant difference in survival between the 2 histologic types of adenocarcinoma and squamous cell carcinoma $(P=.92)$. On the contrary, among patients with body tumors, leiomyosarcoma was associated with worse outcome in comparison with adenocarcinoma $(P=.02)$.

Patients with a DFI of 12 months or more achieved a 5-year survival of $59.8 \%$ (95\% CI, 49.3\%-70.3\%), whereas patients with a DFI of less than 12 months achieved a 5-year survival of $36.8 \%$ (95\% CI, 17.3\%-56.3\%) ( $P=.02$ ) (Figure 2). Excluding 8 patients with pulmonary metastases detected simultaneously with the primary tumor, those survivals were still significantly different $(59.8 \%$ and $17.1 \%$, respectively) $(P<.0001)$. Patients with a DFI of more than 36 months demonstrated no additional survival advantage compared with those with a DFI between 12 and 36 months (5-year survivals, $56.9 \%$ and $52.8 \%$, respectively) $(P=.37$ ).

A significant difference in survival according to the number of resected metastases is shown in Figure 3. The 5 -year survivals of patients with 3 or less metastases and 4 or more metastases were $58.5 \%$ (95\% CI, 48.4\%-68.5\%) and $32.1 \%(95 \% \mathrm{CI}, 9.1 \%-55.1 \%)$, respectively $(P=.03)$.
Patients with a single metastasis $(\mathrm{n}=77)$ achieved a 5-year survival of $60.5 \%$ (95\% CI, 48.9\%-72.0\%). However, among the patients with a DFI of more than 12 months, the 13 patients with more than 4 metastases achieved a 5-year survival of $49.2 \%$, and the survival was not significantly different from that of the other 85 patients with 3 or less lesions $(P=.88)$.

In regard to the resected tumor size, there was a significant difference between patients whose tumors had a maximum diameter of less than $3 \mathrm{~cm}$ and patients whose tumors had a maximum diameter of $3 \mathrm{~cm}$ or more $(P=.01)$ (Figure 4$)$.

Lymph node dissection itself did not statistically affect prolonged survival $(P=.76)$. Among the 45 patients who underwent lymphadenectomy, those with positive lymph nodes $(\mathrm{n}=16)$ had poorer survival than those with negative lymph nodes (5-year survival, $30.3 \%$ vs $60.2 \%$ ). However, there was no significant difference in the survival between these 2 groups $(P=.25)$.

Eight patients $(6 \%)$ with extrapulmonary metastasis had a poorer prognosis than the patients with no extrapulmonary metastasis (5-year survival, $43.8 \%$ vs $57.4 \%$ ), but the survival between the 2 groups was not statistically different $(P=.88)$.

Multivariable analysis was performed for patients with cervical squamous cell carcinoma, cervical adenocarcinoma, endometrial adenocarcinoma, or leiomyosarcoma 


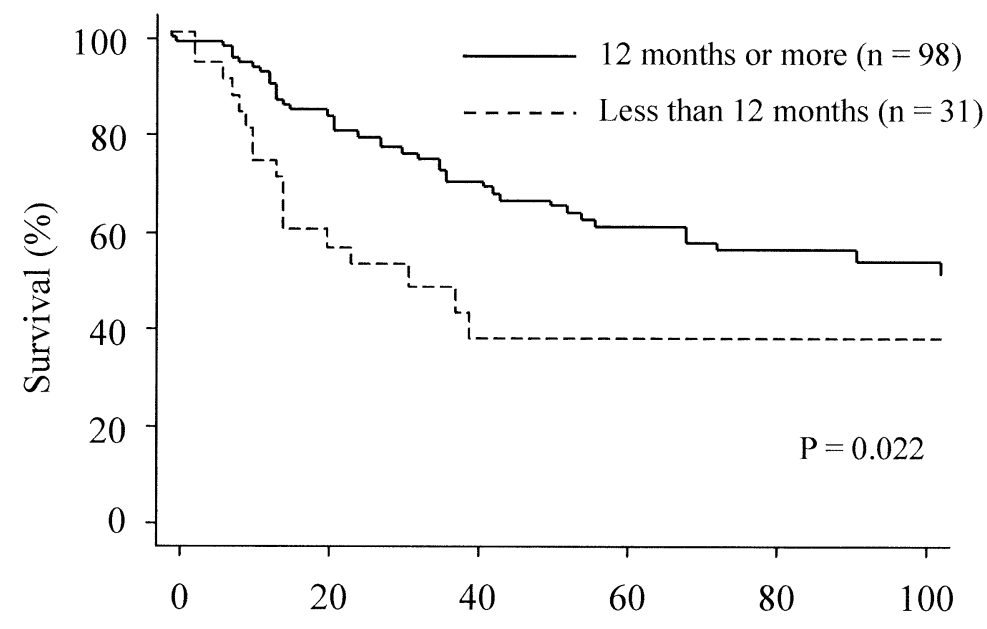

Patients at risk

Time (months)

$\begin{array}{lllllll}\text { 12 or more } & 98 & 76 & 58 & 39 & 28 & 22 \\ \text { Less than } 12 & 31 & 16 & 7 & 6 & 5 & 5\end{array}$

Figure 2. Survival curves from the time at initial metastasectomy: influence of DFI. Log-rank test: $P=.022$.

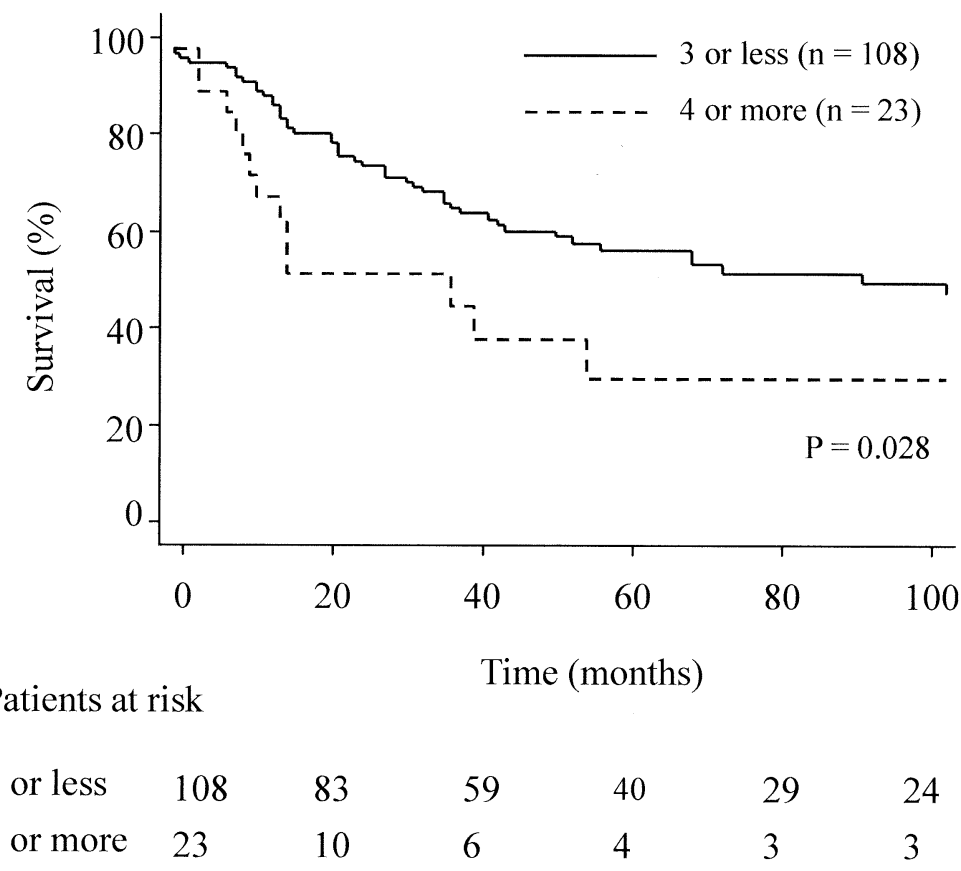

Figure 3. Survival curves from the time at initial metastasectomy: influence of the number of resected tumors. Log-rank test: $\boldsymbol{P}=\mathbf{. 0 2 8}$.

(Table 2). In addition to the 12 cases of miscellaneous histologic types, the 16 cases of choriocarcinoma were excluded from the analysis because effective chemotherapy was available for the latter cases. Variables for the multi- variable analysis were as follows: combination of site and histology, age, DFI, multiplicity of metastases, and tumor size. After mutual adjustment, a short DFI of less than 12 months alone was related to risk of death. 


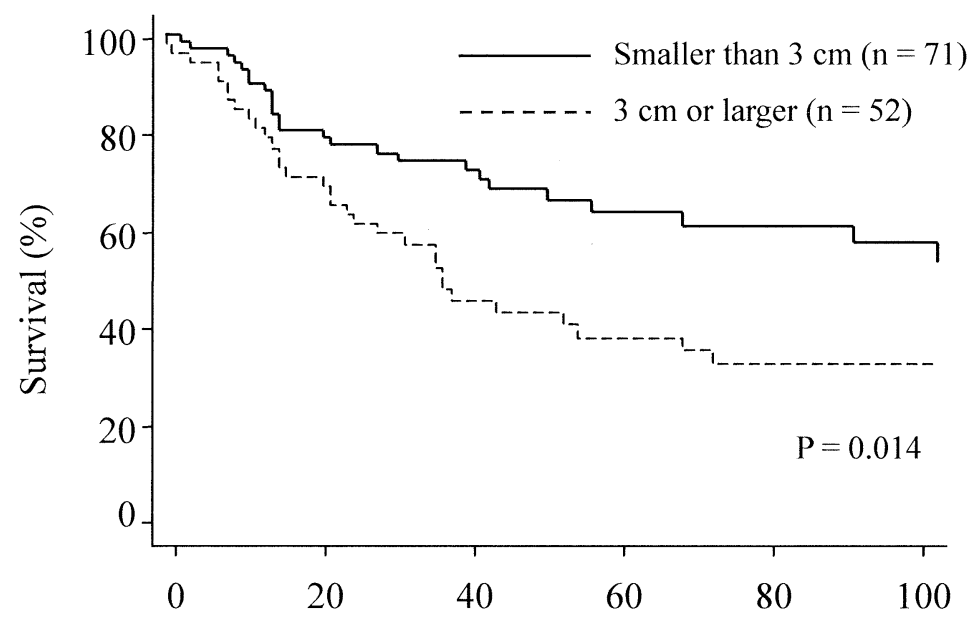

Patients at risk

Time (months)

$\begin{array}{lllllll}<3 \mathrm{~cm} & 71 & 50 & 40 & 23 & 17 & 15 \\ \geq 3 \mathrm{~cm} & 52 & 36 & 19 & 15 & 11 & 8\end{array}$

Figure 4. Survival curves from the time at initial metastasectomy: influence of resected tumor size. Log-rank test: $P=.014$.

\section{Discussion}

The concept of metastasectomy is surgical tumor eradication that may contribute to prolonged survival. In general, the indication for pulmonary metastasectomy includes the following: the primary tumor is controlled or controllable; there is no extrapulmonary disease; the medical status is adequate to tolerate lung resection; complete resection is possible; and no better treatment is available. ${ }^{9}$ A surgical approach for selected patients has been regarded as beneficial treatment, although almost all studies in the past were retrospective and without a control group. The surgical results after pulmonary metastasectomy of gynecologic cancers have also been published. ${ }^{3,10}$ Nevertheless, because those reports contained a relatively small number of cases, their data were inadequate to analyze the evidence of the thoracic surgical procedure. Therefore, to analyze the clinical, pathologic, and prognostic information of a large number of patients with pulmonary resection for metastatic uterine malignancies, we conducted a retrospective study of the patients enrolled in the Metastatic Lung Tumor Study Group of Japan.

In cervical cancers, the most common site of extrapelvic spread is the lung, ${ }^{11}$ and $80 \%$ to $90 \%$ of cervical cancers are squamous cell carcinomas. Seki and colleagues ${ }^{12}$ reported a 5 -year survival of $52 \%$ in 32 patients with cervical squamous cell carcinoma who underwent pulmonary resection. The survival data were similar to the present findings. The survival of patients with cervical adenocarcinoma was comparable to the survival of patients with squamous cell car-
TABLE 2. Relation between clinicopathologic characteristics and survival: Multivariable analysis with Cox proportional hazards model

\begin{tabular}{lrrr}
\hline Characteristic & $\begin{array}{r}\text { Hazard } \\
\text { ratio }\end{array}$ & 95\% CI & $\begin{array}{c}\boldsymbol{P} \\
\text { value }\end{array}$ \\
\hline Tumor histology & & & \\
$\quad$ Cervical squamous cell carcinoma & 1.00 & Reference & \\
$\quad$ Cervical adenocarcinoma & 0.97 & $0.44-2.14$ & .98 \\
$\quad$ Endometrial adenocarcinoma & 0.50 & $0.20-1.21$ & .12 \\
$\quad$ Leiomyosarcoma & 1.11 & $0.37-3.36$ & .80 \\
Age (y) & & & \\
$\quad<65$ & 1.00 & Reference & \\
$\geq 65$ & 0.86 & $0.45-1.66$ & .68 \\
$\begin{array}{l}\text { Disease-free interval (mo) } \\
\geq 12\end{array}$ & 1.00 & Reference & \\
$\quad 1-11$ & 2.26 & $1.06-4.78$ & .01 \\
Number of resected metastases & & & \\
$\quad \geq 4$ & 1.00 & Reference & \\
$1-3$ & 0.60 & $0.27-1.32$ & .26 \\
Tumor size (cm) & & & \\
$\quad \geq 3.0$ & 1.00 & Reference & \\
$\quad<3.0$ & 0.60 & $0.34-1.09$ & .10 \\
\hline
\end{tabular}

$\mathrm{Cl}$, Confidence interval.

cinoma, although the number of patients was small. The present results encourage surgery to improve survival for highly selected patients with pulmonary metastases from cervical adenocarcinoma.

In endometrial malignancies, Anderson and colleagues ${ }^{10}$ reported a median survival of 46 months in 6 patients with 
endometrial adenocarcinoma who underwent pulmonary resection, and Otsuka and colleagues ${ }^{13}$ described a median survival of 50 months in 5 patients. Survival of our 23 patients with endometrial adenocarcinoma was more favorable (5-year survival of 75.7\%). However, these results may be attributable to the patients' backgrounds, that is, 18 of the patients (78\%) had less than 3 metastases, and 21 patients (91\%) underwent complete resection. Levenback and associates ${ }^{14}$ documented a 5 -year survival of $43 \%$ in 45 patients with leiomyosarcoma, which was similar to the present survival findings of patients with leiomyosarcoma and cervical cancer.

Prognostic indicators to select patients who will benefit from pulmonary metastasectomy have been analyzed for various tumor types. ${ }^{15}$ The number of metastases, bilaterality of lesions, DFI, and tumor doubling time are factors generally associated with survival after surgical resection. Shorter DFI or tumor doubling time may reflect tumor aggressiveness and indicate poor postresection survival. ${ }^{16,17}$ The present analysis confirmed that a longer DFI $(\geq 12$ months) strongly influenced good postthoracotomy survival. However, limited to the patients with a single metastasis, the group with a DFI of less than 12 months $(\mathrm{n}=16)$ showed a 5-year survival of $48.6 \%$. Therefore, a short DFI should not preclude patients from pulmonary resection.

The optimum number of metastases in candidates for surgery with curative intent was not clear. In the present series, the patients with 3 or less metastases showed better survival than those with more than 3 metastases, but this was not significantly different in the multivariable analysis. Limited to patients with a DFI of more than 12 months, the present findings indicate that metastasectomy for multiple lesions is effective to improve survival. Girard and associates ${ }^{18}$ investigated the surgical results of 44 patients with a large number of pulmonary metastases and concluded that the prognostic value depends on the resectability rather than the number of metastases. They reported a 5-year survival of $28 \%$ after metastasectomy for patients with 8 or more lesions, which was not significantly different from the survival of patients with less than 8 lesions. After thorough case-by-case selection of patients with a long DFI, pulmonary metastasectomy may enable prolonged survival irrespective of the number of metastases.

\section{Conclusion}

It is recommended that patients with resectable lung metastases from uterine malignancies undergo metastasectomy. Carefully selected patients, especially those with a DFI of more than 12 months, would have potential survival benefits.

We thank Satoshi Honjo, MD, Epidemiology Unit, Tochigi Cancer Center, for statistical review.

\section{References}

1. Pastorino U, Buyse M, Friedel G, Ginsberg RJ, Girard P, Goldstraw P, et al, The International Registry of Lung Metastases. Long-term results of lung metastasectomy: prognostic analyses based on 5206 cases. J Thorac Cardiovasc Surg. 1997;113:37-49.

2. Trek F. Removal of metastatic carcinoma of the lung and mediastinum: suggestions as to technic. Arch Surg. 1930;21:1416-24.

3. Fuller AF Jr, Scannell JG, Wilkins EW Jr. Pulmonary resection for metastases from gynecologic cancers: Massachusetts General Hospital experience, 1943-1982. Gynecol Oncol. 1985;22:174-80.

4. Imachi M, Tsukamoto N, Matsuyama T, Nakano H. Pulmonary metastasis from carcinoma of the uterine cervix. Gynecol Oncol. 1989;33:189-92.

5. Barter JF, Soong SJ, Hatch KD, Orr JW, Shingleton HM. Diagnosis and treatment of pulmonary metastases from cervical carcinoma. $G y$ necol Oncol. 1990;38:347-51.

6. Bouros D, Papadakis K, Siafakas N, Fuller AF Jr. Natural history of patients with pulmonary metastases from uterine cancer. Cancer. 1996;78:441-7.

7. Kaplan EL, Meier P. Nonparametric estimation from incomplete observations. J Am Stat Assoc. 1958;53:457-81.

8. Cox DR. Regression models and life-tables. J R Stat Soc B. 1972;34: $187-220$.

9. McCormack P. Surgical resection of pulmonary metastases. Semin Surg Oncol. 1990;6:297-302.

10. Anderson TM, McMahon JJ, Nwogu CE, Pombo MW, Urschel JD, Driscoll DL, et al. Pulmonary resection in metastatic uterine and cervical malignancies. Gynecol Oncol. 2001;83:472-6.

11. van Nagell JR Jr, Rayburn W, Donaldson ES, Hanson M, Gay EC, Yoneda $\mathbf{J}$, et al. Therapeutic implications of patterns of recurrence in cancer of the uterine cervix. Cancer. 1979;44:2354-61.

12. Seki M, Nakagawa K, Tsuchiya S, Matsubara T, Kinoshita I, Weng SY, et al. Surgical treatment of pulmonary metastases from uterine cervical cancer. Operation method by lung tumor size. J Thorac Cardiovasc Surg. 1992;104:876-81.

13. Otsuka I, Ono I, Akamatsu H, Sunamori M, Aso T. Pulmonary metastasis from endometrial carcinoma. Int J Gynecol Cancer. 2002; 12:208-13

14. Levenback C, Rubin SC, McCormack PM, Hoskins WJ, Atkinson EN, Lewis JL Jr. Resection of pulmonary metastases from uterine sarcomas. Gynecol Oncol. 1992;45:202-5.

15. Putnam JB Jr. Metastatic cancer to the lung. In: DeVita VT Jr, Hellman S, Rosenberg SA, editors. Cancer, principles and practice of oncology. 6th ed. Philadelphia: Lippincott Williams and Wilkins; 2001. p. 2670-89.

16. Roth JA, Putnam JB Jr, Wesley MN, Rosenberg SA. Differing determinants of prognosis following resection of pulmonary metastases from osteogenic and soft tissue sarcoma patients. Cancer. 1985;55: 1361-6.

17. Ishihara $\mathrm{T}$, Kikuchi K, Ikeda $\mathrm{T}$, Yamazaki S. Metastatic pulmonary diseases: biologic factors and modes of treatment. Chest. 1973;63:227-32.

18. Girard P, Baldeyrou P, Le Chevalier T, Lemoine G, Tremblay C, Spielmann M, et al. Surgical resection of pulmonary metastases. Up to what number? Am J Respir Crit Care Med. 1994;149:469-76.

\section{Appendix}

The following institutions participated in this study: Cancer Institute Hospital, Chiba Cancer Center, Chiba University, Hamamatsu University, International Medical Center of Japan, Keio University, National Cancer Center, National Defense Medical College, National Fuji Hospital, National Tokyo Medical Center, Nihon University, Saitama Cancer Center, Saitama Medical School, Tochigi Cancer Center, Toho University, Tokyo Medical University, Tokyo Metropolitan Komagome Hospital, and University of Tokyo. 